\title{
Peroxisome Proliferator-Activated Receptor $\gamma$ Regulates the Expression of Lipid Phosphate Phosphohydrolase 1 in Human Vascular Endothelial Cells
}

\author{
Yazi Huang, Beilei Zhao, Yahan Liu, and Nanping Wang \\ Institute of Cardiovascular Science, Peking University Health Science Center, Beijing 100191, China \\ Correspondence should be addressed to Nanping Wang; nanpingwang2003@yahoo.com
}

Received 27 November 2013; Accepted 1 April 2014; Published 12 May 2014

Academic Editor: Youfei Guan

Copyright (C) 2014 Yazi Huang et al. This is an open access article distributed under the Creative Commons Attribution License, which permits unrestricted use, distribution, and reproduction in any medium, provided the original work is properly cited.

\begin{abstract}
Lipid phosphate phosphohydrolase 1 (LPP1), a membrane ectophosphohydrolase regulating the availability of bioactive lipid phosphates, plays important roles in cellular signaling and physiological processes such as angiogenesis and endothelial migration. However, the regulated expression of LPP1 remains largely unknown. Here, we aimed to examine a role of peroxisome proliferatoractivated receptor $\gamma(\mathrm{PPAR} \gamma)$ in the transcriptional control of LPP1 gene expression. In human umbilical vein endothelial cells (HUVECs), quantitative reverse transcriptase polymerase chain reaction (qRT-PCR) demonstrated that activation of PPAR $\gamma$ increased the mRNA level of LPP1. Chromatin immunoprecipitation assay showed that PPAR $\gamma$ binds to the putative PPARresponsive elements (PPREs) within the $5^{\prime}$-flanking region of the human LPP1 gene. Genomic fragment containing 1.7-kilobase of the promoter region was cloned by using PCR. The luciferase reporter assays demonstrated that overexpression of PPAR $\gamma$ and rosiglitazone, a specific ligand for PPAR $\gamma$, could significantly upregulate the reporter activity. However, site-directed mutagenesis of the PPRE motif abolished the induction. In conclusion, our results demonstrated that PPAR $\gamma$ transcriptionally activated the expression of LPP1 gene in ECs, suggesting a potential role of PPAR $\gamma$ in the metabolism of phospholipids.
\end{abstract}

\section{Introduction}

Lipid phosphate phosphohydrolases (LPPs), also known as phosphatidate phosphohydrolase-2 (PAP-2), are the $\mathrm{Mg}^{2+}$-independent and $\mathrm{N}$-ethylmaleimide-insensitive $\mathrm{N}$ glycosylated integral membrane ectophosphohydrolase $[1,2]$. LPPs catalyze the dephosphorylation of a range of lipid phosphates, such as lysophosphatidic acid (LPA) and sphingosine 1-phosphate (S1P) [3, 4]. Extracellular LPA and S1P bind to the G-protein-coupled receptors (GPCRs) and exert a number of pathophysiological actions, such as angiogenesis, platelet activation, inflammation, smooth muscle cells (SMCs) proliferation and migration, and cardiovascular remodeling $[4,5]$. LPPs hydrolyze these lipid phosphates to terminate their signaling actions or generate new signaling molecules [6]. Three isoforms of LPPs (LPP1, LPP2, and LPP3) have been found [7]. LPP1 negatively regulates lysophospholipid signalings by degrading the bioactive lysophospholipids released from platelets and modulates their effects on the cell proliferation, migration, inflammation, coagulation, and wound healing $[5,6]$. The activity of LPP1 is mainly regulated through de novo expression rather than posttranslational modification such as phosphorylation. Expression of LPP1 was induced by androgens in human prostatic adenocarcinoma cells and decreased in ovarian cancers $[8,9]$. However, transcriptional mechanism underlying the regulation expression of the LPP1 remains largely unclear.

Peroxisome proliferator-activated receptors (PPARs) are a family of ligand-activated nuclear receptors and transcription factors [10]. Among three PPAR isoforms $(\alpha, \beta / \delta$, and $\gamma), \operatorname{PPAR} \gamma$ is predominantly expressed in adipose tissue and also in vasculature including vascular smooth muscle cells (VSMCs) and endothelial cells (ECs) [11, 12]. PPAR $\gamma$ forms a heterodimer with RXR and binds to the PPAR response elements (PPREs) in the promoter region of target genes [13]. When activated by various natural and synthetic ligands such as prostaglandin metabolite 15d-PGJ2 [14] and the 
insulin sensitizer rosiglitazone [15], PPAR $\gamma$ transactivates the gene expression and regulates adipogenesis [16] and insulin response [17]. In addition, PPAR $\gamma$ possesses antiatherogenic and anti-inflammatory actions in ECs $[18,19]$. Therefore, we attempted to examine a role of PPAR $\gamma$ in the regulation of LPP1 gene expression in ECs.

\section{Materials and Methods}

2.1. Cell Culture and Reagents. Human umbilical vein endothelial cells (HUVECs) were cultured as previously described [20]. Bovine aortic endothelial cells (BAECs) were harvested from bovine aorta and maintained in DMEM with 10\% FBS [21]. Rosiglitazone, GW501516, and GW9662 were obtained from Cayman Chemical. Polyclonal rabbit anti-PPAR $\gamma$ and rabbit IgG were from Santa Cruz Biotechnology. Luciferase assay reagent, MMLV reverse transcriptase, Taq polymerase, restriction enzymes (XhoI, NheI), and DNA ligase were from Promega Corporation. Lipofectamine 2000 and Trizol reagent were obtained from Invitrogen. The QuikChange sitedirected mutagenesis kit was from Stratagene Corporation.

2.2. Adenoviral Infection. Cells were infected with adenoviruses encoding the wild type human $\operatorname{PPAR} \alpha, \beta / \delta$, or $\gamma 1$ (AdWT-PPAR $\alpha$ or Ad-WT-PPAR $\beta / \delta$, Ad-WT-PPAR $\gamma$ ) together with Ad-tTA, which encodes a tetracycline-responsive transactivator. These viral constructs were previously described and used at 50 multiplicities of infection [22, 23]. Infected cells were maintained in the presence or absence of tetracycline $(0.1 \mu \mathrm{g} / \mathrm{mL}$, a tet-off expression) for 48 hours as described [20].

\subsection{RNA Extraction and Real-Time Quantitative RT-PCR} ( $q R T-P C R)$. Total RNA was extracted with Trizol reagent and reverse transcribed into cDNA with $\mathrm{M}-\mathrm{MLV}$ reverse transcriptase with oligo-dT as a primer. Real-time PCR was performed with SYBR-green dye and Taq polymerase in the DNA Engine Opticon real-time system (Bio-Rad Laboratories Inc.). GAPDH was used as an internal control. The primer sequences are: LPP1 5'-TCAACTGCAGCGATGGTTAC (forward), $5^{\prime}$-GCCCACATAAATGGATACGG (reverse); GAPDH $5^{\prime}$-ACCACAGTCCATGCCATCAC (forward), 5'-TCCACCACCCTGTTGCTGTA (reverse).

2.4. Plasmids, Mutation, Transfection, and Reporter Assay. The genomic fragment containing -1921 to -221 bp upstream of the transcription start site of human LPP1 gene was PCR amplified from human genomic DNA with the primers (5'-CTTGATAGTACAACAGGGTCA and 5'-TCAGGTGGTCTCCGAACT) with flanking sites of NheI and XhoI. The amplified product was subcloned into the pGL3basic luciferase vector to generate the pGL3/LPP1-luc. The Quickchange site-directed mutagenesis kit was used to generate the pGL3/mLPP1-luc by disruption of the putative PPRE site (from -624 to $-611 \mathrm{bp}$ ) with the use of
TABLE 1: The sequences of the primers for ChIP assay.

\begin{tabular}{cc}
\hline hLPP1 PPRE1 & $5^{\prime}$-AGGTGACGGTGGATGGAA-3' \\
& $5^{\prime}$-CCTTTGTTGTAGAAGCCCTT-3' \\
\hline hLPP1 PPRE2 & $5^{\prime}$-AGGGCTTCTACAACAAAGG-3' \\
& $5^{\prime}$-ATCATCCATCCTCGATACCT-3' \\
\hline \multirow{2}{*}{ hLPP1 PPRE3 } & $5^{\prime}$-CGAGGATGGATGATTTAGCA-3' \\
& $5^{\prime}$-GAGCCCTTTCTCACTTAGG-3' \\
\hline
\end{tabular}

the mutagenic primers: $5^{\prime}$-GAGGGATTCTGGCTAAAGGCG(A)GT(G)TCCC(AA) GGT(G)CTTCTACAAC and $5^{\prime}$ -

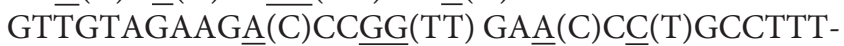
AGCCAGAATCCCTC. The plasmids were transfected together with the pRSV- $\beta$-gal plasmid into BAECs by using Lipofectamine 2000. Luciferase activity was measured with the luciferase assay kit and normalized with $\beta$-galactosidase activity.

2.5. Chromatin Immunoprecipitation. HUVECs were infected with Ad-WT-PPAR $\gamma$ and, $48 \mathrm{~h}$ later, cross-linked with $1 \%$ formaldehyde. The sheared chromatin DNAs were immunoreacted with $2 \mu \mathrm{g}$ anti-PPAR $\gamma$ antibody (or IgG as negative control) and precipitated with protein $A / G$ sepharose beads. The eluted immunoprecipitates were digested with proteinase K. DNA was amplified by qPCR with the primers flanking the putative PPREs. The primers for ChIP assay were shown in Table 1 .

2.6. Statistical Analysis. Data are expressed as mean \pm SEM from at least three independent experiments. Statistical analyses were performed by using one-way ANOVA. The $P$ values less than 0.05 were considered statistically significant.

\section{Results}

3.1. PPREs Are Recurrent Motifs in the $5^{\prime}$-Flanking Region of Human LPP1 Gene. We analyzed the human LPP15'-flanking (NC_000005.9) using MatInspector (http://www.genomatix .de/) and identified three putative PPRE motifs, respectively, locating at $-418 \mathrm{bp}$ (AGGTCAACGTTGA), $-548 \mathrm{bp}$ (AATTCAACGGTGA), and -611 bp (AGGTCAAGGGCTT) upstream of the transcriptional start site of human LPP1 gene (Figure 1).

3.2. PPARY Upregulates LPP1 Gene Expression in ECs. To examine whether PPAR $\gamma$ regulates $L P P 1$, we infected HUVECs with Ad-WT-PPAR $\gamma$ together with Ad-tTA in the presence or absence of tetracycline $(0.1 \mu \mathrm{g} / \mathrm{mL})$ for $24 \mathrm{~h}$. Then, cells were treated with the PPAR $\gamma$ ligand rosiglitazone $(5 \mu \mathrm{M})$ for $24 \mathrm{~h}$. The qRT-PCR results showed that mRNA level of LPP1 was significantly induced in ECs activated with rosiglitazone or overexpressing $\operatorname{PPAR} \gamma$. Rosiglitazone further augmented the induction by PPAR $\gamma$ overexpression (Figure 2).

To investigate whether other two isoforms of PPARs also have similar effects, we also infected the ECs with Ad-WT$\operatorname{PPAR} \alpha$ or Ad-WT-PPAR $\delta$ and treated with their specific 


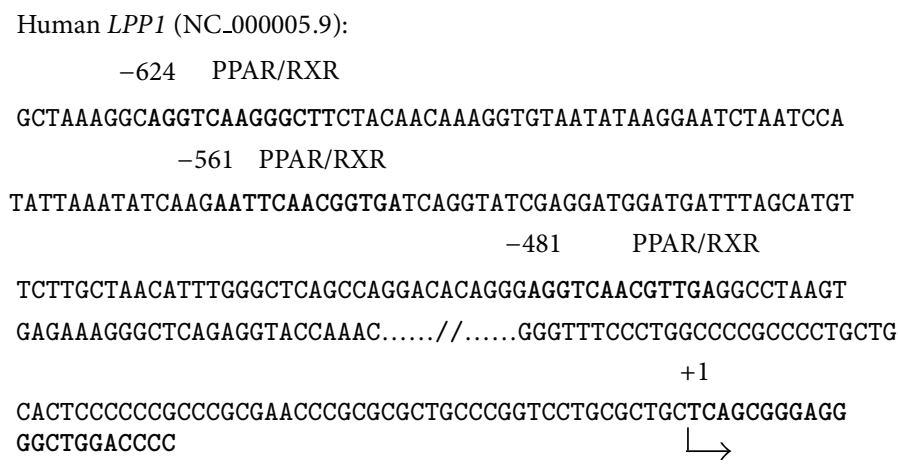

FIGURE 1: Putative PPAR-responsive elements (PPREs) in $5^{\prime}$-flanking region of the human LPP1 gene. Three putative PPREs were located in $5^{\prime}$-flanking region of the human LPP1 gene (NC_000005.9). Nucleotide numbers are relative to the transcription start site $(+1$, arrow).

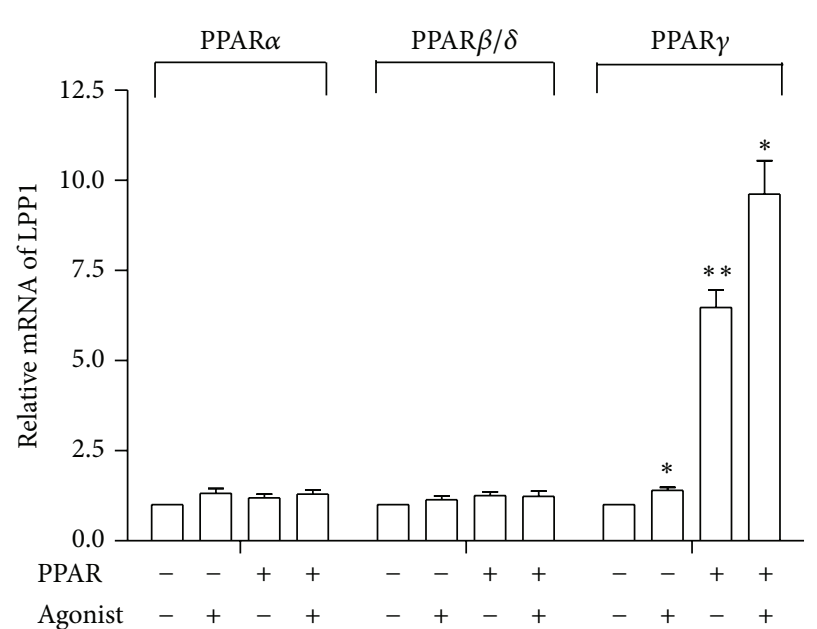

FIGURE 2: PPAR $\gamma$ increases LPP1 expression in mRNA levels. Confluence HUVECs were coinfected with adenoviruses expressing different isoforms of human PPARs together with Ad-tTA. Cells were maintained in the presence or absence of tetracycline for $24 \mathrm{~h}$ and then treated with the selective agonists (fenofibrate, GW501516, or rosiglitazone) or vehicle (DMSO). LPP1 mRNA levels were normalized to GAPDH and expressed as mean \pm SEM of three independent experiments. ${ }^{*} P<0.05 ;{ }^{* *} P<0.01$ versus control.

agonists fenofibrate $(5 \mu \mathrm{M})$ and GW501516 $(1 \mu \mathrm{M})$ for $24 \mathrm{~h}$. LPP1 mRNA level were not affected by neither PPAR $\alpha$ nor $\operatorname{PPAR} \beta / \delta$ overexpression. Similarly, PPAR $\alpha$ and PPAR $\beta / \delta$ agonists had no effect on LPP1 expression (Figure 2).

In order to examine whether the effect of rosiglitazone was specific for PPAR $\gamma$, we used GW9662, a selective antagonist, to pretreat ECs before the exposure. As shown in Figure 3, PPAR $\gamma$ antagonism significantly attenuated the LPP1 induction by rosiglitazone. Taken together, these results indicated that $L P P 1$ gene was induced by PPAR $\gamma$ activation.

3.3. PPAR $\gamma$ Binds to the PPRE in the Promoter of Human LPP1 Gene. Sequence analysis of the $5^{\prime}$-flanking region of human LPP1 gene revealed three putative PPRE motifs. To examine whether PPAR $\gamma$ binds to these regions, ChIP assay was performed with the anti-PPAR $\gamma$ antibody and IgG as control.

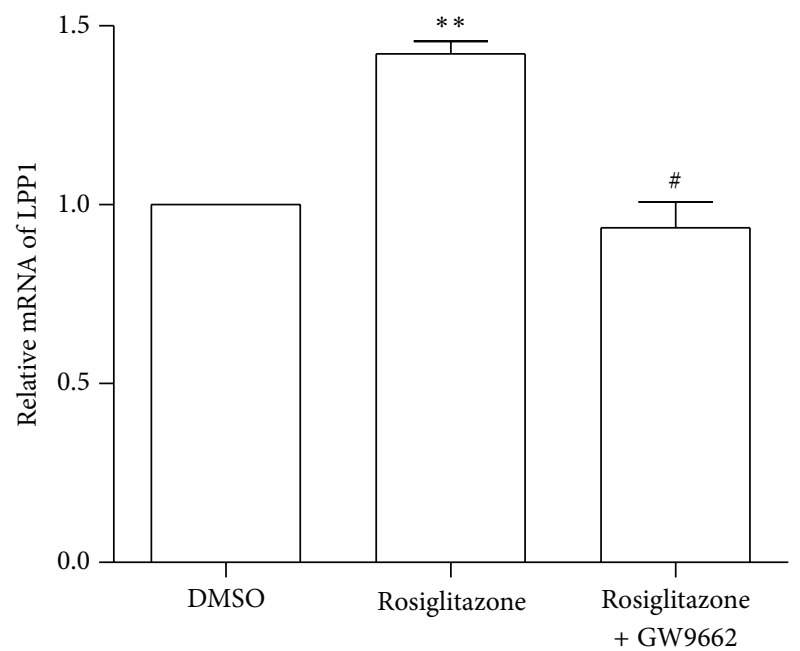

FIGURE 3: PPAR $\gamma$ antagonist attenuates the induction of LPP1 by rosiglitazone. HUVECs were pretreated with GW9662 $(20 \mu \mathrm{M})$ before the exposure to rosiglitazone. Total RNA were extracted $36 \mathrm{~h}$ later and assessed by using qRT-PCR for LPP1 mRNA expression. ${ }^{* *} P<0.01$, versus control (DMSO); ${ }^{\#} P<0.05$, versus rosiglitazone.

The results showed that PPAR $\gamma$ could bind to the PPRE located at $-624 /-611$ bp upstream of the human LPP1 gene, while the two proximal sites at $-481 /-468$ and $-561 /-548$ had no binding (Figure 4). This result suggested that the PPRE at $-624 /-611$ might mediate the induction by $\operatorname{PPAR} \gamma$.

3.4. PPAR $\gamma$ Increases the Promoter Activity of Human LPP1 Gene via Binding to PPRE3. To further examine whether PPAR $\gamma$ promotes the LPP1 gene transcription activity, we constructed pGL3/LPP1-luc reporter driven by the fragment containing three putative PPREs (Figure 5(a)). BAECs were transfected with pGL3/LPP1-luc plasmid. Luciferase assay showed that the reporter activity was increased by rosiglitazone or overexpression of PPAR $\gamma$ (Figure 5(b)). However, site-directed mutagenesis of the PPRE at -624/-611 abolished the induction by $\operatorname{PPAR} \gamma$, indicating that the PPRE at $-624 /-611$ is the cis-element mediating the PPAR $\gamma$ transactivation. 

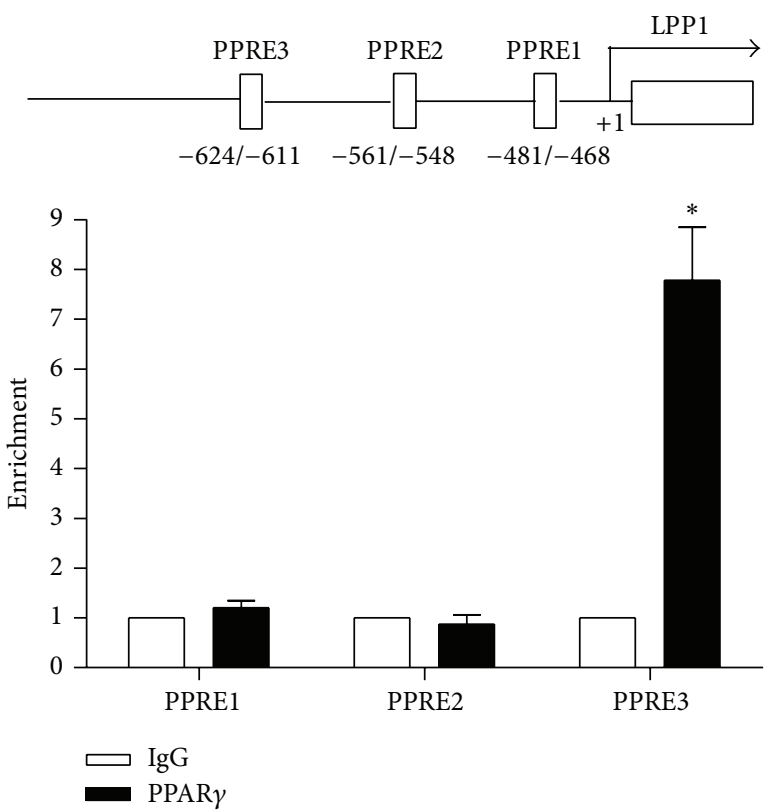

FIGURE 4: PPAR $\gamma$ binds to the PPRE within the 5 -flanking region of LPP1. HUVECs were coinfected with Ad-WT-PPAR $\gamma$ and Ad-tTA for $48 \mathrm{~h}$. ChIP assays were performed with the antibodies against PPAR $\gamma$ or IgG as a negative control. Immunoprecipitated DNA fragments were detected by $\mathrm{qPCR}$ with the use of specific primers spanning the DNA segments containing the predicted PPREs of LPP1 promoter. Data were mean \pm SEM of three independent experiments. ${ }^{*} P<0.05$ versus control.

\section{Discussion}

In the present study, we have demonstrated a transcriptional mechanism regulating the expression of $L P P 1$ gene. We provided novel evidence that PPAR $\gamma$ and its specific agonist rosiglitazone positively regulate the transcription of $L P P 1$ gene in ECs. We also identified the PPRE motif within the regulatory region of the $L P P 1$ gene that mediates the action of PPAR $\gamma$.

Elucidation of the transcriptional regulation of LPP1 is of physiological importance because LPP1 is a key enzyme responsible for the catabolism of LPA and S1P which are the bioactive lipid phosphates [5]. Therefore, given the mass and extensive distribution of ECs, the induction of LPP1 expression may lead to a profound decrease in the concentrations of LPA and S1P, both in circulation and in the tissues, and exert important biological effects. Although $\operatorname{PPAR} \gamma$ has its major roles in the regulation of adipogenesis and insulin sensitivity, it also has a variety of protective effects on cardiovascular functions ranging from atherogenesis to blood pressure regulation $[24,25]$. The finding that PPAR $\gamma$ induces LPP1 expression in ECs may provide new insights into the molecular mechanisms underlying the cardiovascular effects of PPAR $\gamma$ modulation.

LPP1 is an ectoenzyme with its active sites located on the outer surface of plasma membrane. It degrades extracellular LPA to monoacylglycerol, which can be taken into cells to produce intracellular LPA by acylglycerol kinase.

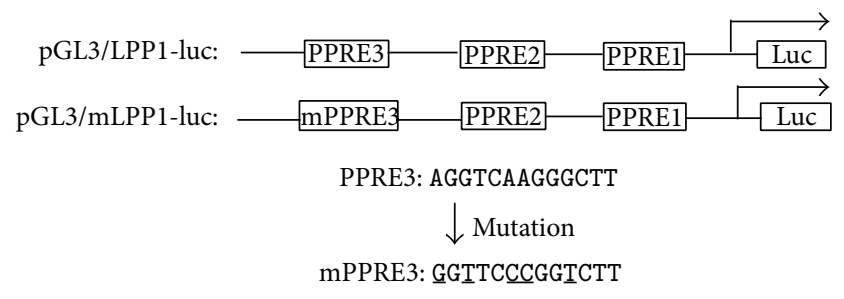

(a)

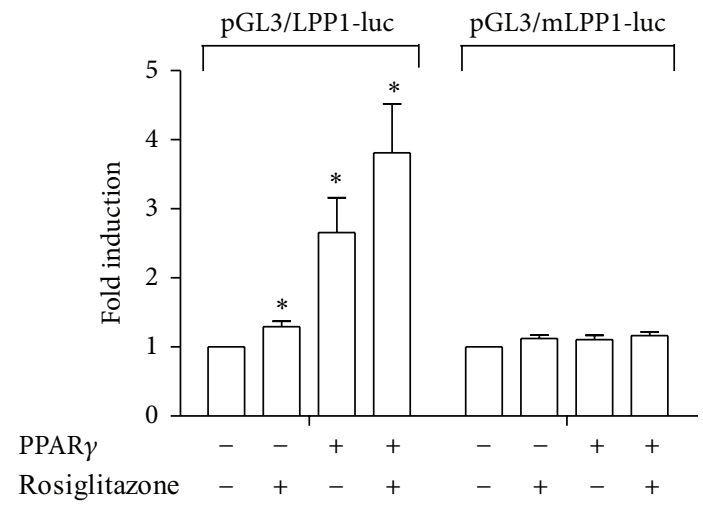

(b)

FIGURE 5: PPAR $\gamma$ increases the promoter activity of LPP1 via binding to PPRE. (a) The pGL3/LPP1-luc and pGL3/mLPP1-luc plasmids with the $1.7 \mathrm{~kb}$ of $5^{\prime}$-flanking region of the human $L P P 1$ gene with 3 putative PPREs and the mutations depicted. (b) BAECs were transfected with pGL3/LPP1-luc or pGL3/mLPP1-luc plasmids together with $\beta$-gal plasmids. Data were fold induction of luciferase activity and expressed as mean \pm SEM of four independent experiments. ${ }^{*} P<0.05 ;{ }^{* *} P<0.01$ versus control.

Intriguingly, intracellular LPA was known to be an agonist for PPAR $\gamma[26,27]$. Thus, it is postulated that the regulation of LPP1 by PPAR $\gamma$ may act as positive loop for extracellular LPA degradation. In human atherosclerotic lesions, LPA was accumulated in the lipid core of the plaques and promoted the development of atherosclerosis in vivo [28, 29]. Lipoproteinderived LPA promoted the atherosclerosis in animal models [30]. In contrast, PPAR $\gamma$ agonists thiazolidinediones (TZD) reduced atherosclerotic plaques both in diabetic patients and in animal models [31]. Therefore, whether the induction of LPP1 and ensuing decrease in LPA contribute to the antiatherosclerotic effect of PPAR $\gamma$ remains to be investigated. In addition, the effects of PPAR $\gamma$ activation on the protein level, enzymatic activity of LPP1, and extracellular levels of LPA and S1P need to be examined in the future.

\section{Conflict of Interests}

The authors declare that there is no conflict of interests regarding the publication of this paper.

\section{Acknowledgments}

This study was supported by Grants from the National Science Foundation of China (81220108005 and 81221061) 
and the Ministry of Science and Technology of China (2010CB912500).

\section{References}

[1] D. N. Brindley and D. W. Waggoner, "Mammalian lipid phosphate phosphohydrolases," Journal of Biological Chemistry, vol. 273, no. 38, pp. 24281-24284, 1998.

[2] D. English, M. Martin, K. A. Harvey et al., "Characterization and purification of neutrophil ecto-phosphatidic acid phosphohydrolase," Biochemical Journal, vol. 324, no. 3, pp. 941-950, 1997.

[3] D. W. Waggoner, A. Gómez-Muñoz, J. Dewald, and D. N. Brindley, "Phosphatidate phosphohydrolase catalyzes the hydrolysis of ceramide 1- phosphate, lysophosphatidate, and sphingosine 1-phosphate," Journal of Biological Chemistry, vol. 271, no. 28, pp. 16506-16509, 1996.

[4] J. Chun, E. J. Goetzl, T. Hla et al., "International Union of Pharmacology. XXXIV. Lysophospholipid receptor nomenclature," Pharmacological Reviews, vol. 54, no. 2, pp. 265-269, 2002.

[5] J. S. Karliner, "Lysophospholipids and the cardiovascular system," Biochimica et Biophysica Acta, vol. 1582, no. 1-3, pp. 216221, 2002.

[6] V. A. Sciorra and A. J. Morris, "Roles for lipid phosphate phosphatases in regulation of cellular signaling," Biochimica et Biophysica Acta, vol. 1582, no. 1-3, pp. 45-51, 2002.

[7] R. Roberts, V. A. Sciorra, and A. J. Morris, "Human type 2 phosphatidic acid phosphohydrolases: Substrate specificity of the type $2 \mathrm{a}, 2 \mathrm{~b}$, and $2 \mathrm{c}$ enzymes and cell surface activity of the 2a isoform," Journal of Biological Chemistry, vol. 273, no. 34, pp. 22059-22067, 1998.

[8] W. Ulrix, J. V. Swinnen, W. Heyns, and G. Verhoeven, "Identification of the phosphatidic acid phosphatase type 2a isozyme as an androgen-regulated gene in the human prostatic adenocarcinoma cell line LNCaP," Journal of Biological Chemistry, vol. 273, no. 8, pp. 4660-4665, 1998.

[9] Y. Tan, R. Yu, and J. M. Pezzuto, "Betulinic acid-induced programmed cell death in human melanoma cells involves mitogen-activated protein kinase activation," Clinical Cancer Research, vol. 9, no. 7, pp. 2866-2875, 2003.

[10] T. Lemberger, O. Braissant, C. Juge-Aubry et al., "PPAR tissue distribution and interactions with other hormone-signaling pathways," Annals of the New York Academy of Sciences, vol. 804, pp. 231-251, 1996.

[11] O. Braissant, F. Foufelle, C. Scotto, M. Dauça, and W. Wahli, "Differential expression of peroxisome proliferator-activated receptors (PPARs): Tissue distribution of PPAR- $\alpha,-\beta$, and $-\gamma$ in the adult rat," Endocrinology, vol. 137, no. 1, pp. 354-366, 1996.

[12] Y. E. Chen, M. Fu, J. Zhang et al., "Peroxisome proliferatoractivated receptors and the cardiovascular system," Vitamins \& Hormones, vol. 66, pp. 157-188, 2003.

[13] K. Schoonjans, J. Peinado-Onsurbe, A. M. Lefebvre et al., "PPAR $\alpha$ and PPAR $\gamma$ activators direct a distinct tissue-specific transcriptional response via a PPRE in the lipoprotein lipase gene," EMBO Journal, vol. 15, no. 19, pp. 5336-5348, 1996.

[14] B. M. Forman, P. Tontonoz, J. Chen, R. P. Brun, B. M. Spiegelman, and R. M. Evans, "15-deoxy- $\Delta 12$, 14-prostaglandin $\mathrm{J} 2$ is a ligand for the adipocyte determination factor PPAR $\gamma$," Cell, vol. 83, no. 5, pp. 803-812, 1995.
[15] J. M. Lehmann, L. B. Moore, T. A. Smith-Oliver, W. O. Wilkison, T. M. Willson, and S. A. Kliewer, "An antidiabetic thiazolidinedione is a high affinity ligand for peroxisome proliferatoractivated receptor $\gamma$ (PPAR $\gamma)$," Journal of Biological Chemistry, vol. 270, no. 22, pp. 12953-12956, 1995.

[16] S. R. Farmer, "Regulation of PPAR $\gamma$ activity during adipogenesis," International Journal of Obesity, vol. 29, supplement 1, pp. S13-S16, 2005.

[17] J. O. Nehlin, J. P. Mogensen, I. Petterson et al., "Selective PPAR agonists for the treatment of type 2 diabetes," Annals of the New York Academy of Sciences, vol. 1067, no. 1, pp. 448-453, 2006.

[18] A. B. Reiss and M. E. Vagell, "PPAR $\gamma$ activity in the vessel wall: anti-atherogenic properties," Current Medicinal Chemistry, vol. 13, no. 26, pp. 3227-3238, 2006.

[19] V. Pasceri, H. D. Wu, J. T. Willerson, and E. T. H. Yeh, "Modulation of vascular inflammation in vitro and in vivo by peroxisome proliferator-activated receptor- $\gamma$ activators," Circulation, vol. 101, no. 3, pp. 235-238, 2000.

[20] N. Wang, L. Verna, N. G. Chen et al., "Constitutive activation of peroxisome proliferator-activated receptor- $\gamma$ suppresses proinflammatory adhesion molecules in human vascular endothelial cells," Journal of Biological Chemistry, vol. 277, no. 37, pp. 34176-34181, 2002.

[21] N. Wang, L. Verna, H.-L. Liao, A. Ballard, Y. Zhu, and M. B. Stemerman, "Adenovirus-mediated overexpression of dominant-negative mutant of c-Jun prevents intercellular adhesion molecule-1 induction by LDL: a critical role for activator protein-1 in endothelial activation," Arteriosclerosis, Thrombosis, and Vascular Biology, vol. 21, no. 9, pp. 1414-1420, 2001.

[22] Y. Fan, Y. Wang, Z. Tang et al., "Suppression of proinflammatory adhesion molecules by PPAR-delta in human vascular endothelial cells," Arteriosclerosis, Thrombosis, and Vascular Biology, vol. 28, no. 2, pp. 315-321, 2008.

[23] P. Zhang, Y. Wang, Y. Fan, Z. Tang, and N. Wang, "Overexpression of adiponectin receptors potentiates the antiinflammatory action of subeffective dose of globular adiponectin in vascular endothelial cells," Arteriosclerosis, Thrombosis, and Vascular Biology, vol. 29, no. 1, pp. 67-74, 2009.

[24] J. Li and N. Wang, "Peroxisome proliferator-activated receptor$\gamma$ in vascular biology," Cardiovascular and Hematological Disorders, vol. 7, no. 2, pp. 109-117, 2007.

[25] R. M. Touyz and E. L. Schiffrin, "Peroxisome proliferatoractivated receptors in vascular biology-molecular mechanisms and clinical implications," Vascular Pharmacology, vol. 45, no. 1, pp. 19-28, 2006.

[26] R. L. van der Bend, J. de Widt, E. J. Van Corven, W. H. Moolenaar, and W. J. Van Blitterswijk, "Metabolic conversion of the biologically active phospholipid, lysophosphatidic acid, in fibroblasts," Biochimica et Biophysica Acta, vol. 1125, no. 1, pp. 110-112, 1992.

[27] T. M. McIntyre, A. V. Pontsler, A. R. Silva et al., "Identification of an intracellular receptor for lysophosphatidic acid (LPA): LPA is a transcellular PPAR $\gamma$ agonist," Proceedings of the National Academy of Sciences of the United States of America, vol. 100, no. 1, pp. 131-136, 2003.

[28] W. Siess, K. J. Zangl, M. Essler et al., "Lysophosphatidic acid mediates the rapid activation of platelets and endothelial cells by mildly oxidized low density lipoprotein and accumulates in human atherosclerotic lesions," Proceedings of the National Academy of Sciences of the United States of America, vol. 96, no. 12, pp. 6931-6936, 1999. 
[29] E. Rother, R. Brandl, D. L. Baker et al., "Subtype-selective antagonists of lysophosphatidic acid receptors inhibit platelet activation triggered by the lipid core of atherosclerotic plaques," Circulation, vol. 108, no. 6, pp. 741-747, 2003.

[30] Z. Zhou, P. Subramanian, G. Sevilmis et al., "Lipoproteinderived lysophosphatidic acid promotes atherosclerosis by releasing CXCL1 from the endothelium," Cell Metabolism, vol. 13, no. 5, pp. 592-600, 2011.

[31] P. Zimmet, "Addressing the insulin resistance syndrome: a role for the thiazolidinediones," Trends in Cardiovascular Medicine, vol. 12, no. 8, pp. 354-362, 2002. 


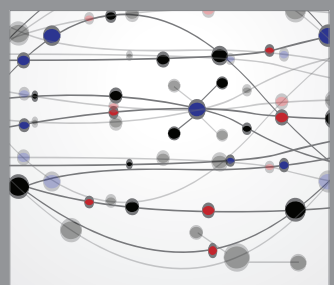

The Scientific World Journal
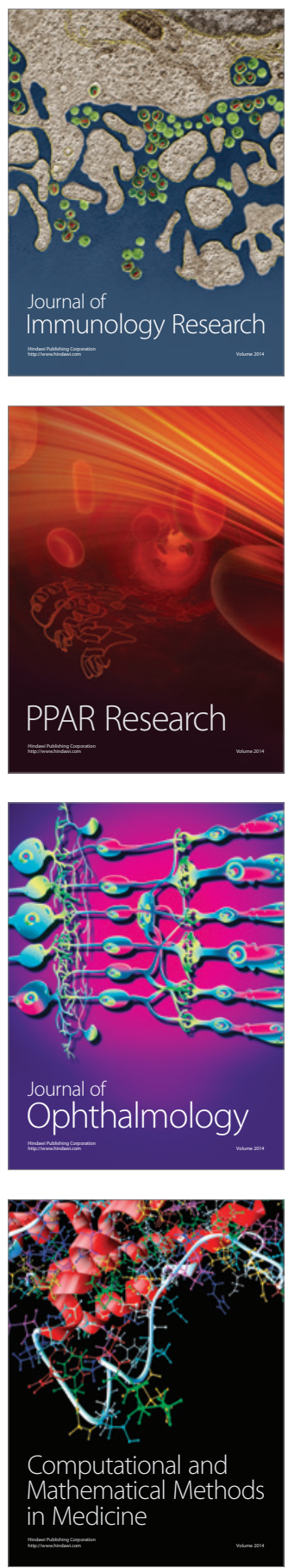

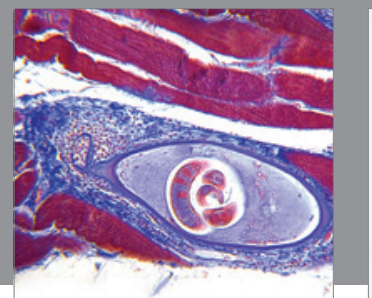

Gastroenterology

Research and Practice
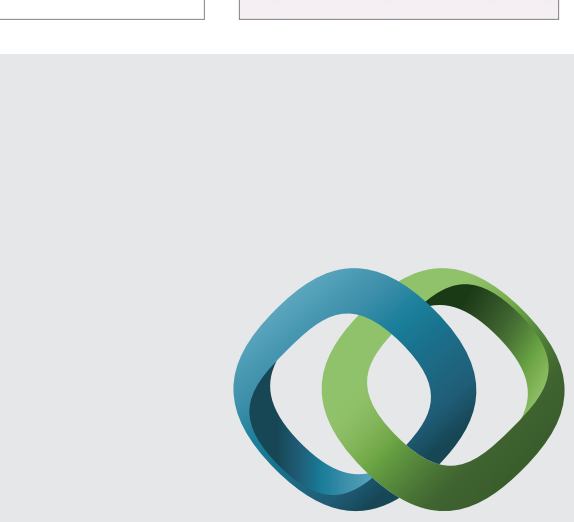

\section{Hindawi}

Submit your manuscripts at

http://www.hindawi.com
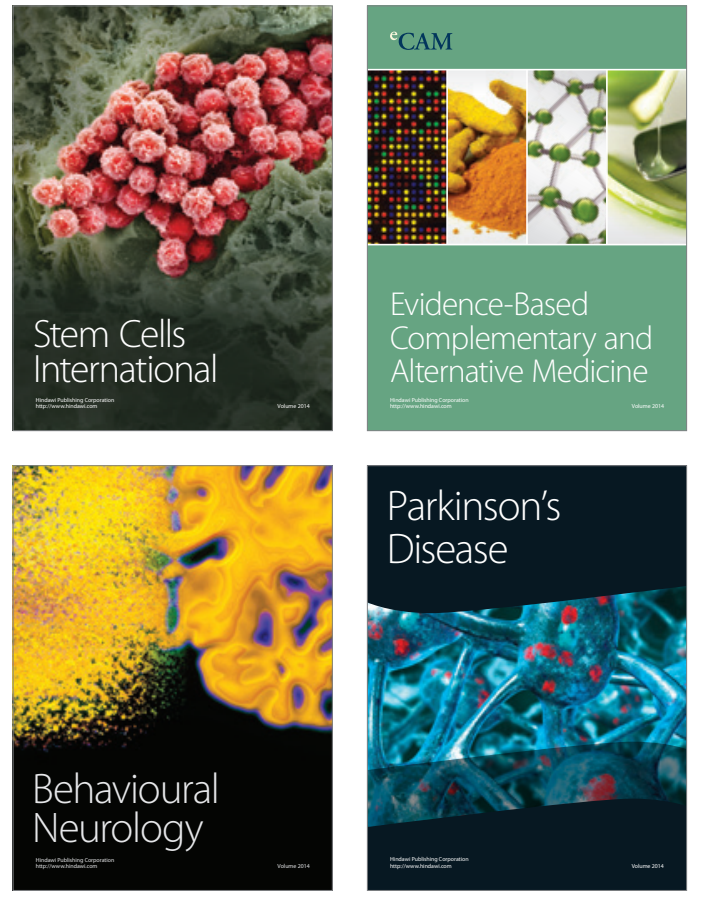
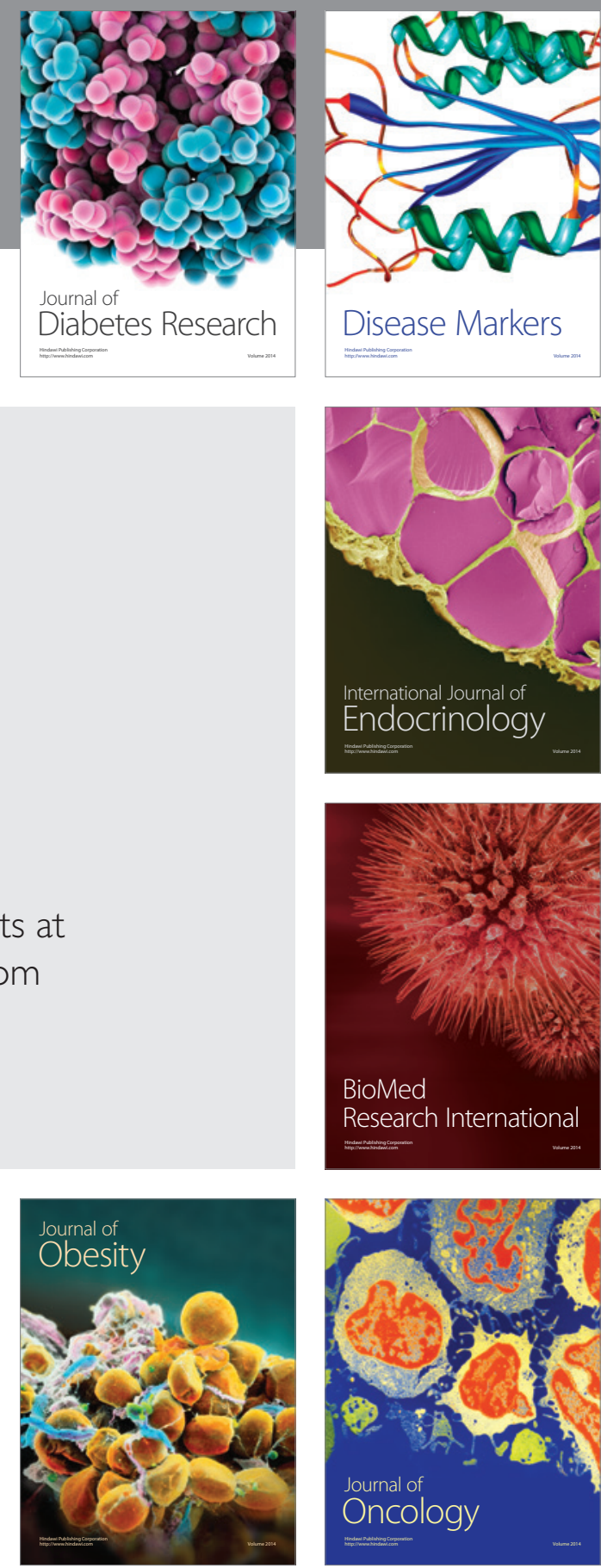

Disease Markers
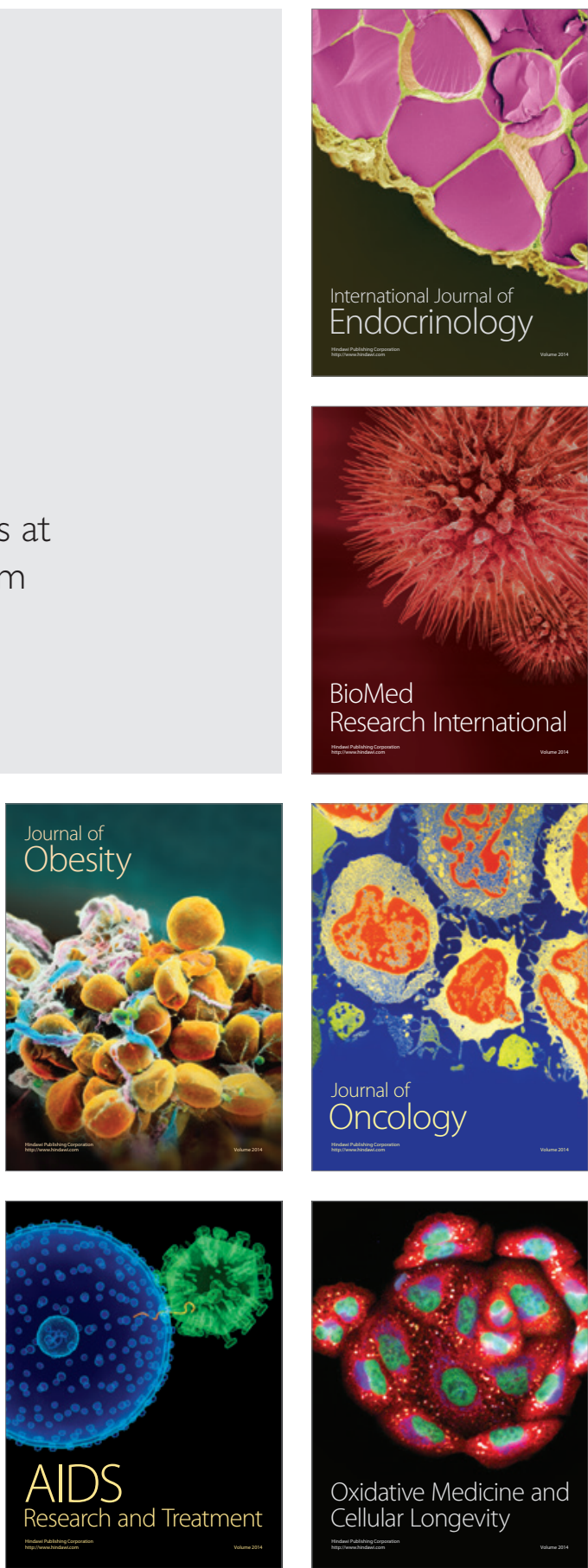